\title{
Subungual Ewing sarcoma/PNET tumor family of the great toe: a case report
}

Fariba Binesh ${ }^{1}$, Mohammad Sobhanardekani ${ }^{2}$, Saeedeh Zare ${ }^{3}$, Nasim Behniafard ${ }^{4}$

${ }^{1}$ M.D. of Pathology, Professor, Department of Pathology, Shahid Sadoughi University of Medical Sciences, Yazd, Iran

${ }^{2}$ M.D. of Radiology, Assistant Professor, Department of Radiology, Shahid Sadoughi University of Medical Sciences, Yazd, Iran

${ }^{3}$ Department of Radiology, Shahid Sadoughi University of Medical Sciences, Yazd, Iran

${ }^{4}$ M.D., General Physician, Otorhinolaryngology Research Center, Shahid Sadoughi University of Medical Sciences, Yazd, Iran

\section{Type of article: Case report}

\begin{abstract}
Ewing's sarcoma is seen mainly in patients less than 18. This aggressive tumor generally affects the axial skeleton and only rarely involves the acral regions. Ewing's sarcoma in the foot is inordinately scarce. Clinical features are uncertain and can imitate other common diseases. This paper presents a case of 62 -year-old malewith complaints of pain and swelling of the subungual area of his right great toe. The lesion was excised, and histopathological diagnosis of Ewing's sarcoma was made. Histopathological examination, supported by immunochemical methods, remains the mainstay of diagnosis. Surgical ablation along with chemotherapy is the therapy of choice. To our knowledge, this is the first report of Ewing's sarcoma involving the nail bed of the great toe without bone erosion. The key messages of this case report is "Subungual Ewing sarcoma is a rare case, and Ewing's sarcoma must be kept in mind for acral lesions, especially in the adult population."
\end{abstract}

Keywords: Ewing's sarcoma, chemotherapy, nail

\section{Introduction}

Arthur Purdy Stout described an undifferentiated round cell sarcoma involving the ulnar nerve in a 42-year-old man in1918. Later, James Ewing presented a similar tumor that involved radius bone in a 14-year-old girl and called it "diffuse endothelioma of bone. "However, the first case of extra skeletal Ewing's sarcoma was reported by Angervall and Enzinger in 1975. Thereafter, Seemayer described peripheral neuroectodermal tumors arising in the soft tissues (1).The vast majority of Ewing's sarcomas are seen in patients whose ages are less than 20. The rest of the patients are in the range of 20 to 30 . Ewing's sarcoma is extremely rare in patients older than 30 . When the possibility of this tumor is confronted in patients older than 30, the physician must first exclude small-cell carcinoma and large-cell lymphoma from the list of differential diagnoses (2). Although this tumor is stated to comprise almost $6 \%$ of the total malignant bone tumors, it is very rare in the small bones of the hands and feet, where the incidence is not more than $1 \%$ (3). The foot bones most commonly involved include the calcaneus and the metatarsals (4). Here, we present a case of a 62-year-old male with Ewing's sarcoma of the subungual area of the right great toe without bone erosion.

\section{Case presentation}

\subsection{Clinical presentation and history}

An otherwise healthy 62-year-old male presented with pain and swelling of the subungual area of his right great toe for the past eight months. Complaints commenced after a minor local trauma. The patient sought medical attention

\section{Corresponding author:}

Dr Nasim Behniafard, Otorhinolaryngology Research Center, Departments of Otolaryngology, Shahid Sadoughi Hospital, Avicenna Blvd., Safaeieh, Yazd, Iran.

Tel: +98.9132746826, Fax: +98.358224100, Email: nbehniafard@gmail.com

Received: December 28, 2015, Accepted: March 31, 2016, Published: April 2016

iThenticate screening: March 29, 2016, English editing: April 04, 2016, Quality control: April 09, 2016

(C) 2016 The Authors. This is an open access article under the terms of the Creative Commons Attribution-NonCommercialNoDerivs License, which permits use and distribution in any medium, provided the original work is properly cited, the use is non-commercial and no modifications or adaptations are made. 
at a local private clinic at that time. Under the erroneous diagnosis of trauma induced swelling, the nail was removed. This effort was ineffective, and as the swelling and pain progressed, he was referred to our institute.

\subsection{Physical examination}

On physical examination, there was a tender, swollen, ulcerative nodular mass, $2 \times 1.5 \mathrm{~cm}$ in size, at the nail bed of the right great toe (Figure 1). There was no sign of lymphadenopathy. A radiogram of the toe illustrated a radioopaque lesion in the dorsal aspect of the distal phalanx of the right great toe without bone erosion (Figure 2).

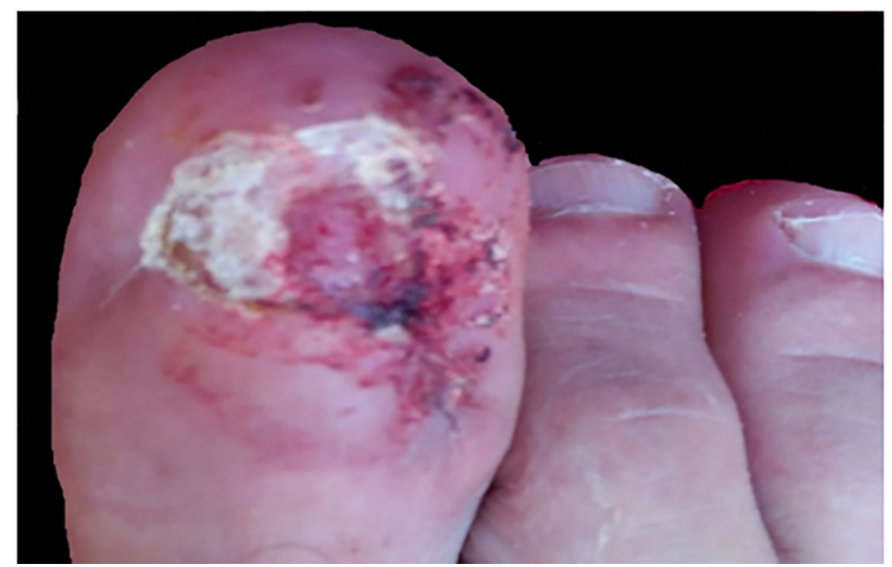

Figure 1. Nodular mass at the nail bed of the right great toe

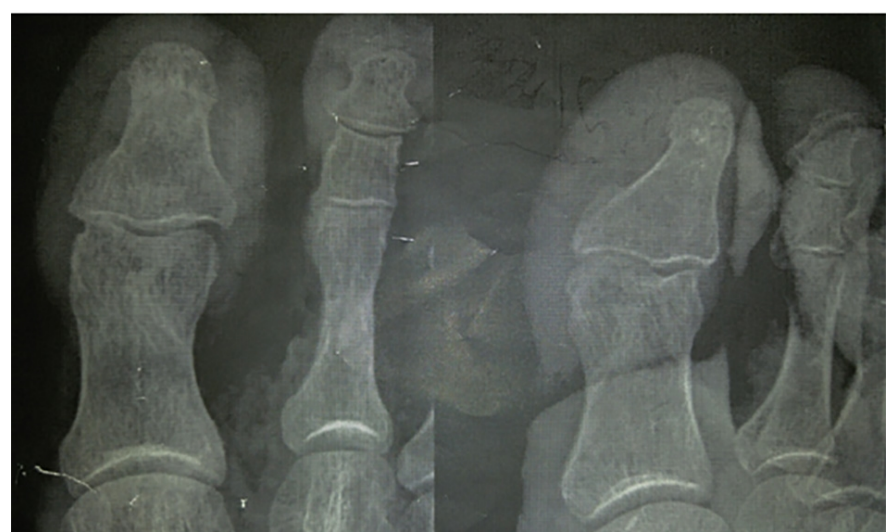

Figure 2. Radiogram of the toe illustrating a radio-opaque lesion in the dorsal aspect of the distal phalanx of the right great toe without bone erosion

\subsection{Imaging}

The CT scan did not indicate any evidence of obvious abnormality in the bone. MRI showed soft tissue signal mass lesion in the mentioned area (Figure 3). The lesion appeared isosignal on T1, and it had a heterogenous signal on T2. In addition, there was non-homogenous enhancement after contrast injection, but the bone marrow signal was unremarkable (Figures 4-A, B, C).

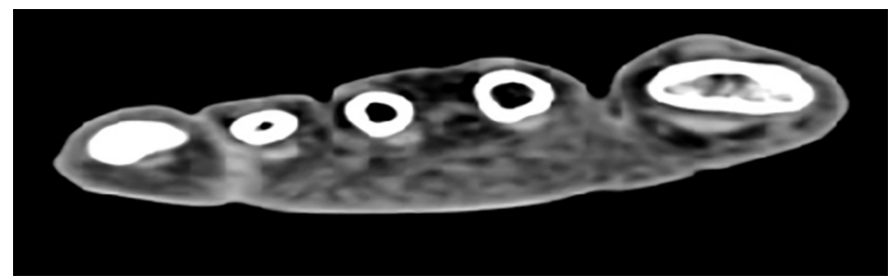

Figure 3. CT- scan showing no evidence of obvious abnormality in the bone 

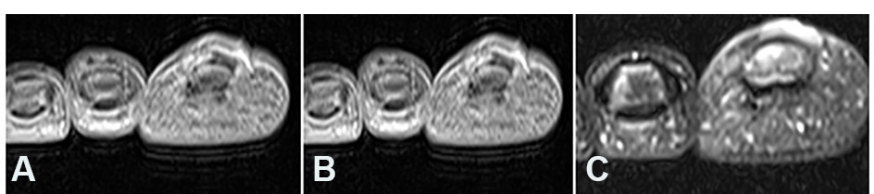

Figure 4. A) Lesion appearing to be isosignal on T1; B) Non-homogenous enhancement after contrast injection; C) Heterogenous lesion signal on $\mathrm{T} 2$

\subsection{Laboratory data and diagnosis}

All laboratory data were within normal limits. An excisional biopsy was performed. Histological examination showed tumoral tissue composed of lobulated pattern separated by hyalinized fibrous septas. Tumor cells showed a solid pattern .Cells were oval or round with a vesicular nucleus and had small amount of eosinophilic cytoplasm (Figure 5). Immunohistochemical studies revealed positive results for vimentin, CD99, and S100 protein, and there were negative results for cytokeratin, desmin, synaptophysin, epithelial membrane antigen, myoglobin, and leukocyte common antigen (Figure 6). The final diagnosis was Ewing's sarcoma.

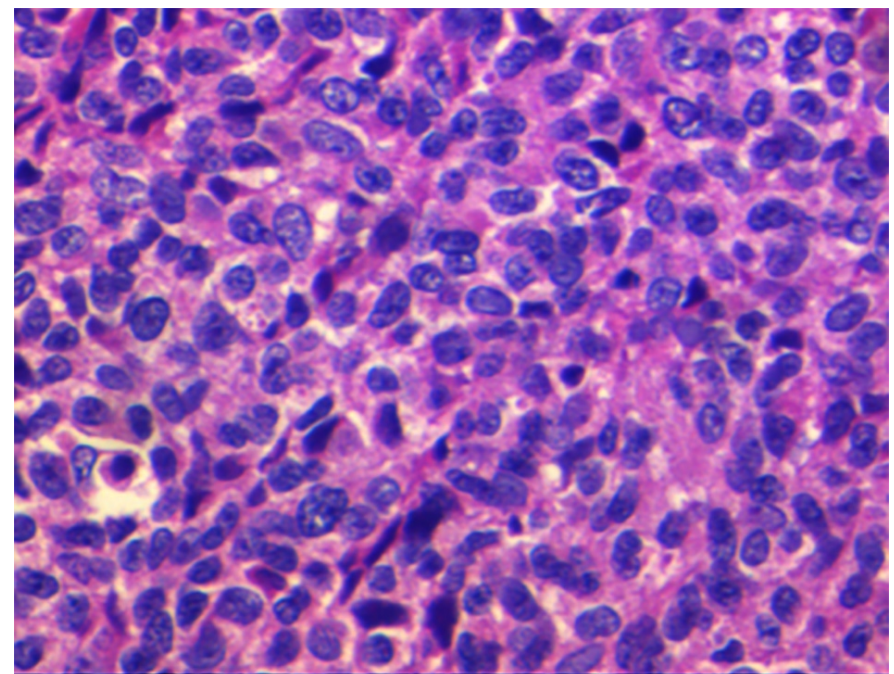

Figure 5. Oval or round tumoral cells with a vesicular nucleus and a small amount of eosinophilic cytoplasm (H\&E $\mathrm{X} 100)$

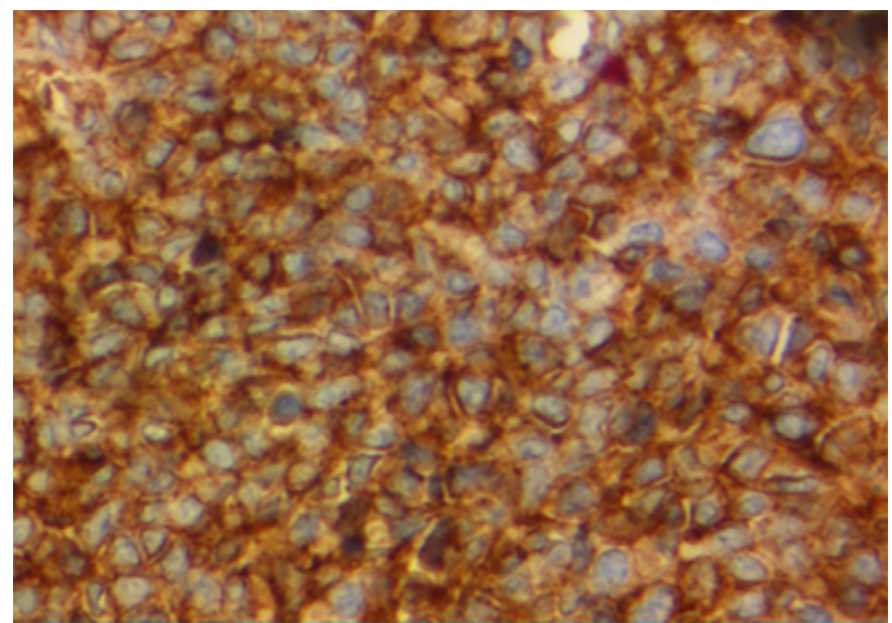

Figure 6. Cells showing positive results for CD99 (IHC stain)

Please note that the titles of figures are not supposed to be complete sentences. 


\subsection{Treatment and follow-up}

The CT scans of the chest, abdomen, and pelvis were normal. The patient was sent for chemotherapy and underwent six cycles of multi-agent chemotherapy (vincristin, dactinomycin, and cyclophosphamide). He is fine now.

\section{Discussion}

Many of the tumors that occur in the rest of the skeletal bones can occur in bones of the hands or feet. Ewing's sarcoma of the hand and foot is a rare entity for which the reported incidence is not more than $0.3 \%$ and occurs mostly in patients' short tubular bones (5). In a report from the Intergroup Ewing Sarcoma Study, 10 (among 377 cases) had Ewing's sarcoma of the foot (6). In a retrospective study of all tumors involving bones of the hands or feet during a period of six years in southern India, the authors found only one case of Ewing's sarcoma of the foot (7). Although Ewing's sarcoma can involve any bone of the foot, the calcaneous bone is the most commonly affected bone (8). It is alleged that calcaneal involvement has an ominous prospect (8). Siddiqui et al. described a patient with calcaneal Ewing's sarcoma with skip metastasis to adjacent tarsal bones (9). Javaid Abmed presented a case of extraosseous Ewing's sarcoma of the great toe with metastasis to the lung (10). Khodamorad Jamshidi reported a case of multifocal Ewing sarcoma involving multiple bones in the foot (11). In the current case, the nail bed was the location of the tumor. Quinlan described a 21-year-old woman who presented with a peripheral primitive neuroectodermal tumour of the distal phalanx of the right hallux (12). Ewing's sarcoma usually occurs between the ages of 10 and 15, and it rarely occurs in patients older than 30 (13). An onset after the third decade of life is very scare, but our patient was 62. In Shantveer's report, the patient was a middle-aged woman with involvement of the head of the right first metatarsal bone (7). There is a slight male predominance (1). Pain and swelling are the main presenting symptoms, and this occurred in our case. Low-grade fever is common. Elevated erythrocyte sedimentation rate and leukocytosis may be observed in these patients. The presented case had no evidence of systemic complaints and had normal laboratory data. Few patients have a history of previous local trauma. The current patient gave a history of local trauma. Plain film radiographs may show a group of non-specific features that are suggestive of malignancy; however, they may not be exclusively indicative of Ewing's sarcoma. In Reinus's study (14), the author showed that a permeative bone lesion with poorly defined margins and an associated soft tissue mass are the most common features. Our case had no evidence of bone erosion. Computed tomography and magnetic resonance imaging showed the osseous extent of the tumor and the presence or absence of the soft-tissue component. The common differential diagnosis includes osteomyelitis, tuberculosis, enchondroma, and benign tumors. Histopathological examination, supported by immunochemical methods, remains the mainstay of diagnosis. As this tumor is rare, there are few reports on its appropriate treatment and long-term outcomes. Management has included both local control, by surgery, and systemic chemotherapy (15). Because of the progress that has been made in the diagnosis and the treatment, the rate of amputations has decreased remarkably. Fortunately, limb salvage has not resulted in a worse prognosis (16). Our patient underwent excisional biopsy and received chemotherapy. With the development of modern chemotherapy, the long-term survival rate has improved to approximately $70 \%$ (17).

\section{Conclusions}

This paper emphasized the fact that Ewing's sarcoma must be kept in mind for acral lesions, especially in the adult population where radiographs can simulate any other possibility and raise the problem of differential diagnosis with other tumors of the soft tissues. Histopathological examination, supported by immunochemical methods, is essential to confirm the diagnosis.

\section{Acknowledgments:}

The authors are indebted to the staff of the Pathology Unit at Shahid Sadoughi Hospital in Yazd, Iran, for their cooperation in this study.

\section{Conflict of Interest:}

There is no conflict of interest to be declared.

\section{Authors' contributions:}

All authors contributed to this project and article equally. All authors read and approved the final manuscript.

\section{References:}

1) Goldblum SWW. Ewing's sarcoma/PNET tumor family and related lesions. In: John R. Goldblum SWW, Andrew L. Folpe, editor. Enzinger and Weiss's Soft Tissue Tumors: Mosby; 2008. p. 945-88. 
2) Dorfman H.D CsB. EWING'S SARCOMA AND RELATED ENT In ES. In: Dorfman H.D CsB, editor. bone tumore: C.V. Mosby; 1998. p. 613.

3) Shekhar A, Korlhalli S, Murgod G. Ewing's sarcoma of proximal phalanx of the hand with skip metastases to metacarpals. Indian J Orthop. 2015; 49(3): 365-8. doi: 10.4103/0019-5413.156229. PMID: 26015641, PMCID: PMC444342.

4) Casadei R, Magnani M, Biagini R, Mercuri M. Prognostic factors in Ewing's sarcoma of the foot. Clin Orthop Relat Res. 2004; (420): 230-8. doi: 10.1097/00003086-200403000-00033. PMID: 15057103.

5) Kissane JM, Askin FB, Foulkes M, Stratton LB, Shirley SF. Ewing's sarcoma of bone: clinicopathologic aspects of 303 cases from the Intergroup Ewing's Sarcoma Study. Hum Pathol. 1983; 14(9): 773-9. doi: 10.1016/S0046-8177(83)80300-1. PMID: 6885037.

6) Escobedo EM, Bjorkengren AG, Moore SG. Ewing's sarcoma of the hand. AJR Am J Roentgenol. 1992; 159(1): 101-2. doi: 10.2214/ajr.159.1.1609680. PMID: 1609680.

7) Uppin SG, Sundaram C, Umamahesh M, Chandrashekar P, Rani YJ, Prasad VB. Lesions of the bones of the hands and feet: a study of 50 cases. Arch Pathol Lab Med. 2008; 132(5): 800-12. PMID: 18466029.

8) Shirley SK, Askin FB, Gilula LA, Vietti TJ, Thomas PR, Siegal GP, et al. Ewing's sarcoma in bones of the hands and feet: a clinicopathologic study and review of the literature. J Clin Oncol. 1985; 3(5): 686-97. PMID: 3998785.

9) Siddiqui YS, Zahid M, Sabir A, Asif N, Kumar G, Akhtar M. Calcaneal Ewing's sarcoma with skip metastases to the adjacent tarsal bones. J Clin Diag Res. 2011; 5: 117-9.

10) Javaid Abmed Bbat NAM, Subail maajid, S. D. Paljor, Subail Basbir I, Wabid Bbat. Ewing's Sarcoma of Big Toe. JK Science. 2003; 5(4): 165-6.

11) Jamshidi K, Shiradi MR. Unusual form and location for a tumor: multiosseous Ewing sarcoma in the foot. Am J Orthop (Belle Mead NJ). 2015; 44(1): E32-5. PMID: 25566563.

12) Quinlan JF, Healy CF, Royston D, Murray P. PNET of the hallux. Ir Med J. 2004; 97(4): 118. PMID: 15200223.

13) Price CH, Jeffree GM. Incidence of bone sarcoma in SW England, 1946-74, in relation to age, sex, tumour site and histology. Br J Cancer. 1977; 36(4): 511-22. doi: 10.1038/bjc.1977.221.

14) Reinus WR, Gilula LA, Shirley SK, Askin FB, Siegal GP. Radiographic appearance of Ewing sarcoma of the hands and feet: report from the Intergroup Ewing Sarcoma Study. AJR Am J Roentgenol. 1985; 144(2): 331-6. doi: 10.2214/ajr.144.2.331. PMID: 3871280.

15) Jerome TJ, Varghese M, Sankaran B. Ewing's sarcoma of the distal phalanx of the little finger. J Hand Surg Eur Vol. 2008; 33(1): 81-2. doi: 10.1177/1753193407087865. PMID: 18332026.

16) Daecke W, Ahrens S, Juergens H, Martini A-K, Ewerbeck V, Kotz R, et al. Ewing's sarcoma and primitive neuroectodermal tumor of hand and forearm. J Cancer Res Clin Oncol. 2005; 131(4): 219-25. doi: 10.1007/s00432-004-0637-9. PMID: 15614525.

17) Wunder JS, Paulian G, Huvos AG, Heller G, Meyers PA, Healey JH. The histological response to chemotherapy as a predictor of the oncological outcome of operative treatment of Ewing sarcoma. J Bone Joint Surg Am. 1998; 80(7): 1020-33. PMID: 9698007. 